\title{
Ultrasound Diagnosis for Preventing Knee Injuries in Cuban High-Performance Athletes
}

\author{
Ricardo Anillo, MD, PhD, MSpMed, Emilio Villanueva, MD, MSpMed, Dayneri León, MD, MSpMed, \\ Armando Pena, MD, MSpMed
}

\begin{abstract}
Introduction Diagnostic evaluation of the musculoskeletal system has traditionally been based on medical history, physical examination, and $\mathrm{x}$-rays (techniques that provide limited information), and more recently on computerized axial tomography and magnetic resonance imaging (both very expensive). Ultrasound, a non-invasive and less expensive method, has become an indispensable tool for diagnosing overuse sports injuries. The Imaging Department at the Cuban Sports Medicine Institute (abbreviated in Spanish as IMD) developed a preventive ultrasound diagnostic imaging method and has applied it for the last 15 years as part of the IMD's medical management of high-performance athletes.
\end{abstract}

Objectives Identify normal ultrasound patterns for knee structures and extensor mechanism alignment, and perform ultrasound imaging of the knee on asymptomatic, high-performance athletes to detect alterations and endogenous predisposing factors to overuse sports injuries as a basis for adopting preventive action.

Methods A descriptive cross-sectional study was conducted of 300 non-athletes (control) and 100 Cuban Olympic athletes (preselected for the 2000 Olympic Games in Sydney, Australia). The IMD's Preventive Ultrasound Diagnostic Imaging Method was used to perform static and dynamic ultrasound examinations of both knees of all subjects (800 knees total) to determine normal patterns, detect structural alterations in the knee, and determine extensor mechanism malalignment. For the latter, Anillo's Patellofemoral Congruence Ultrasound Method was applied to determine the degree of patellar lateralization (RAB angle). Data was processed using descriptive statistics. To compare the ratio of ultrasound knee alterations detected, the Chi-square test was used. Percentiles were calculated based on data from the 600 non-athlete knees and were processed using the SPSS statistics application.

Results Of the 100 athletes studied, 57 were found to have subclinical alterations in one or both knees, distributed as follows: synovitis (30), extensor mechanism malalignment (26), infrapatellar fat pad distortion (15), meniscal echostructure modification (14), ligament echostructure alteration (11), and articular cartilage alteration (7). Analysis of the control group findings established that RAB angle values greater than $13^{\circ}$ for both sexes suggest excessive patellar lateralization with respect to the axial axis of the femur, potentially an endogenous risk factor favoring injury.

Conclusions Preventive ultrasound diagnostic imaging of the knee, performed using IMD's ultrasound scanning methodology and incorporating the normal ultrasound patterns described in this study, enables diagnosis of distortions in the articular and periarticular echostructure prior to the onset of clinical symptoms, as well as observation of endogenous predisposing factors linked to overuse sports injuries. As a result, appropriate measures can be adopted to prevent such injuries and to tailor medical management of high-performance athletes.

Keywords: Diagnostic imaging, ultrasound diagnosis, knee, knee injuries, sports medicine, athletic injuries, sports injuries

\section{INTRODUCTION}

Guaranteed success in sports relies on the proper functioning of the musculoskeletal system; any vulnerability hinders performance. Late diagnosis of an impairment in this system favors the appearance of complications and impedes the practice of highperformance sports, which demand that anatomical structures surpass physiological limits.[1] Therefore, a practical, accessible diagnostic method is needed for early detection of such alterations in high-performance athletes, as well as detection of endogenous predisposing factors for overuse sports injuries, so that timely preventive action may be taken.

Diagnostic evaluation of the musculoskeletal system has traditionally been based on medical history, physical examination and $\mathrm{x}$-rays (techniques that provide limited information), and more recently on computerized axial tomography (CAT) and magnetic resonance imaging (both very expensive). Ultrasound, a noninvasive and less expensive procedure, has become an indispensable tool for diagnosing overuse sports injuries with relative precision. It can also be used for individual prophylactic monitoring to detect endogenous factors that appear to be triggers for, or strongly linked to, the appearance of musculoskeletal system conditions.[2,3]
Since the early 1990s, the Imaging Department of the Cuban Sports Medicine Institute (abbreviated in Spanish as IMD) has been developing a preventive ultrasound diagnostic imaging method for maintaining the integrity of an athlete's musculoskeletal system and obtaining a positive adaptive response to the level of athletic fitness required for specific skills. During this time, this method has been used to evaluate the joints and other injuryprone musculoskeletal structures of most high-performance Cuban athletes at some point during their sports careers. $[1,3,4]$ In the present study, this cumulative experience was applied to early ultrasound detection of alterations preceding clinical manifestations of overuse sports injuries in the knee.

The knee, a joint at high risk for sports injuries, has multiple factors that predispose it towards overuse sports injuries,[5-12] and it is the joint most often referred for ultrasound scan by sports medicine and sports traumatology specialists. [4,12-15] Tendinopathies, synovitis, chrondropathies, medial patellar plica syndrome, and injuries to ligaments and menisci are knee conditions closely linked with turning, jumping, deep knee bends and other movements required in highly competitive sports,[16-18] but in many athletes these injuries are initially asymptomatic.[3] 
A descriptive cross-sectional study was conducted to establish normal ultrasound standards for both extensor mechanism alignment and knee structures; using these standards as reference, ultrasound imaging of asymptomatic, high-performance athletes' knees was performed to detect alterations and endogenous predisposing factors to overuse sports injuries.

\section{METHODS}

Type of study and sample selection The study was conducted during the four years prior to the Olympic Games held in Sydney, Australia, from November 1996 to July 2000, and included two groups: A (control) and B (athletes). Group A was made up of 300 non-athletes (150 of each sex), aged 18 to 36 years, average age 26 years. They were recruited through the Imaging Department of the Hermanos Ameijeiras Hospital in Havana, where they were being seen for transitory symptoms related to a one-time illness, excluding any systemic disorder or knee impairment. The control group was studied to obtain normal ultrasound reference patterns for intra- and periarticular knee structures.

Group B was comprised of 100 asymptomatic, high-performance athletes ( 71 men and 29 women): 20 volleyball players (10 of each sex); 20 baseball players; 4 javelin throwers ( 3 men and 1 woman); 8 gymnasts (4 of each sex); 10 judokas (4 men and 6 women); 12 wrestlers (6 from each discipline: Greco-Roman and freestyle); 4 taekwondo athletes ( 3 men and 1 woman); 3 male swimmers; 10 fencers ( 5 of each sex), 4 divers ( 2 of each sex) and 5 male weightlifters. Average age in this group was 23 years.

Inclusion criteria for Group B was pre-selection for the Olympic Games, and for Group A, similar age and gender as Group B, so that the two groups would be comparable. Other criteria, such as weight and height, were not considered, given the great heterogeneity of these variables in the group of pre-selected athletes. Exclusion criteria for both groups were having had clinical manifestations of knee conditions or a history of knee surgery.

Bioethical Considerations Both the athletes and non-athletes were informed of the characteristics, objectives, methodology and purpose of the research. The study was approved by the IMD's Ethics Committee and participants provided informed consent.
Study design An ultrasound evaluation was performed on both knees of each participant in groups $A$ and $B$, for a total of 800 ultrasound studies. Group A (control) was studied from November 1996 to November 1999 and the results analyzed to identify normal ultrasound patterns for the articular structures evaluated, and normal extensor mechanism alignment. Between November 1999 and July 2000 , the same ultrasound evaluation was performed on Group B and the results compared with the normal reference patterns established. During the course of the study, the international literature was consulted regarding the most frequently observed normal and pathologic ultrasound patterns for different peri- and intrarticular structures, using conventional articular ultrasound procedures.[18,19]

IMD's Preventive Ultrasound Diagnostic Imaging Method was applied, consisting of the following: comparative examination of both knees in longitudinal sections (LS), transverse sections (TS) and oblique sections (OS), using dynamic movements involving isometric muscle contractions, and passive and active knee flexion and extension. To determine patellofemoral congruence, Anillo's Patellofemoral Congruence Ultrasound Method was applied.[3]

Preventive Ultrasound Diagnostic Imaging Method The scan begins in the anterior plane, with a craniocaudal LS, moving down through the midline of the knee from the suprapatellar region to the anterior tibial tubercle. This section allows a full view of the femoral quadriceps tendon up to its insertion in the upper patella. The tendon has an approximate diameter ranging from 5 to $10 \mathrm{~mm}$ and should be evaluated for thickness, continuity and echogenicity.[4] The transducer is placed on top of the kneecap to evaluate the suprapatellar bursa (SPB) or bottom of the subquadricipital sac behind the quadriceps tendon. Under normal conditions, a thin layer of viscous fluid separating the layers of the bursa is observed (Figure 1). Next, a suprapatellar TS scan is performed to determine whether there is fluid towards the lateral or medial recesses of the SPB (Figure 2).

In longitudinal position, the transducer is moved across the entire cortical surface of the kneecap, producing a large acoustic shadow, at the lower end of which the patellar tendon (PT) originates. The PT has a uniform thickness ranging from 3 to $5 \mathrm{~mm}$.[3,4]

Figure 1: Longitudinal Section (LS) Ultrasound Imaging of the Anterior Suprapatellar Region of the Knee and Thigh

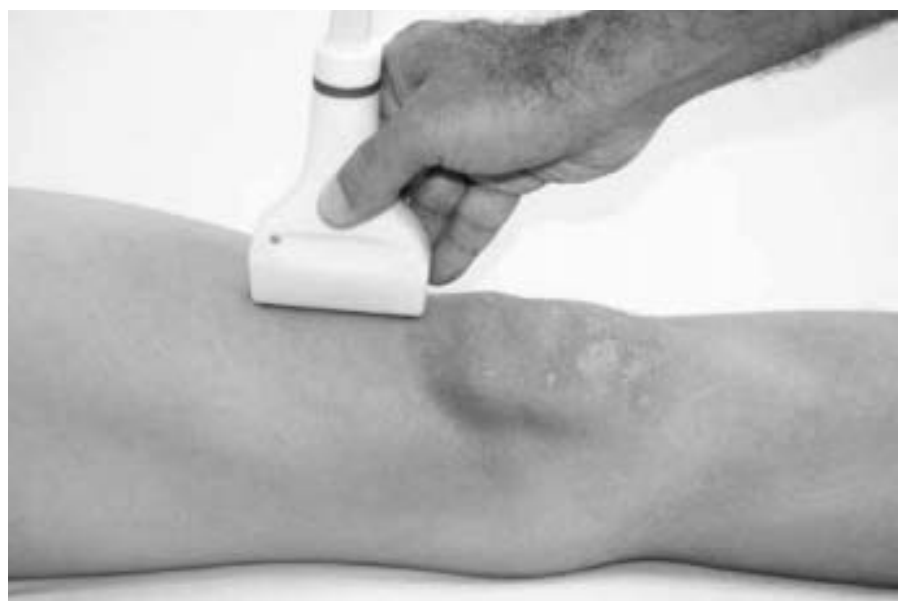

LS transducer position.

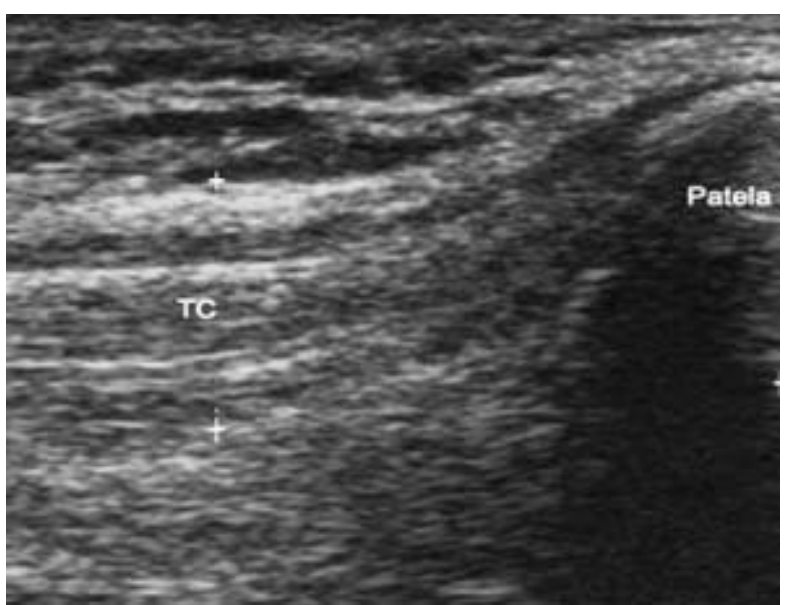

Normal ultrasound image.

TC: quadriceps tendon 
Behind the patellar tendon and in front of the articular surface of the femoral condyles, a mass of heterogeneous echogenicity can be observed corresponding to the infrapatellar fat pad (Figure 3).

The study continues with imaging of the articular space using parapatellar LS and TS, which can be evaluated using stress movements in valgus (to explore the medial meniscus) and in varus (for the lateral meniscus). These movements make it easier to see the anterior horns and medial segments of the menisci. The medial collateral ligament appears longitudinally attached, forming part of a group of structures that adopt a trilaminar aspect on the ultrasound, called the capsuloligamentous complex (Figure 4), while the lateral collateral ligament is completely independent, appearing in its entirety from its origin at the lateral femoral epicondyle to its insertion at the fibula (Figure 5).[4] In addition, but in ventral decubitus, the other components of the external quadruple complex are explored: tendons for the popliteal muscle, biceps femoris and the iliotibial band.

Examination of the posterior side of the joint is completed with an exploration of the popliteal fossa and the muscular plane that converge in this region, starting from the lower third of the thigh and moving down to the upper third of the lower leg. A lateral-medial scan is performed, allowing observation of the muscles in the region and their tendons: the posterior side of the semimembranous muscle, the semitendinous muscle and the medial gastrocnemius, which run through the internal posterior side of the knee, and the biceps femoris and lateral gastrocnemius, which run towards its external posterior edge, as well as the vascular structures in the region (Figure 6).[3,4]
To evaluate extensor mechanism alignment, Anillo's Patellofemoral Congruence Ultrasound Method was applied.[3] In the infrapatellar TS image, a bisected line was traced from the intercondylar notch (femoral trochlea) to the center of the infrapatellar fat pad and then, locating the patellar tendon, which has an ovoid echostructure, another line was traced from the center of the PT to the origin of the bisected line at the intercondylar notch.

The angle that is formed -named RAB angle after the author's initials - can be used to measure the degree of patellar lateralization statically (extensor mechanism relaxed) and dynamically (quadriceps contracted), and thereby determine if there is malalignment of the knee extensor mechanism (Figure 7).

Data processing Descriptive statistics methods were used to statistically process the data. To compare the ratio of ultrasound knee alterations detected in each group, the Chi-square test was used, and Relative Risk (RR) was calculated with a 95\% Confidence Interval (Cl). The statistical application Epidat version 3.0 was used. Percentiles were calculated based on data from the 600 non-athlete knees and were processed using the SPSS statistics application, version 12.0 for Windows.

Equipment Sigma 210 high-resolution ultrasound equipment (Kontron Instruments, France) was used, with a $7.5 \mathrm{MHz}$ linear transducer and a $14 \mathrm{MHz}$ trapezoidal transducer; occasionally, specific couplers were used to study very superficial soft areas.

Figure 2: Transverse Section (TS) Ultrasound Imaging of the Anterior Suprapatellar Region of the Knee

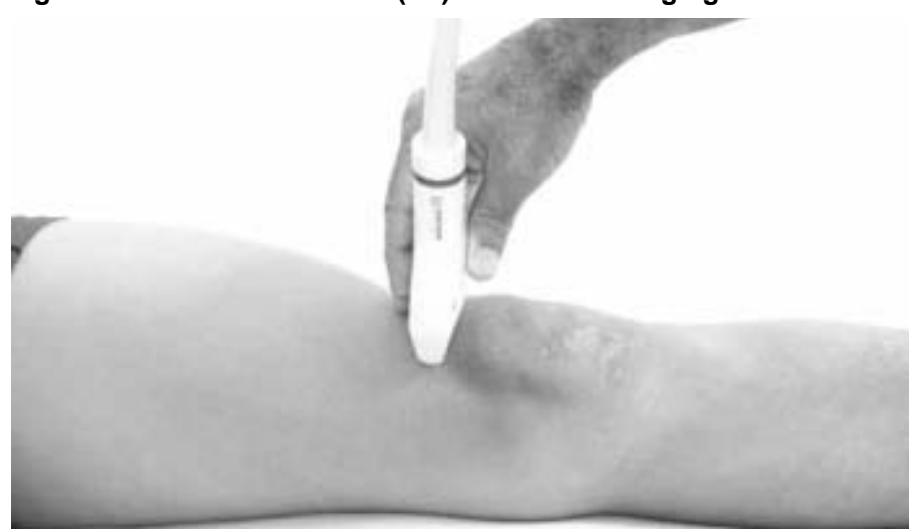

TS transducer position.

Figura 3: Longitudinal Section (LS) Ultrasound Imaging of the Anterior Region (Patellar and Infrapatellar) of the Knee
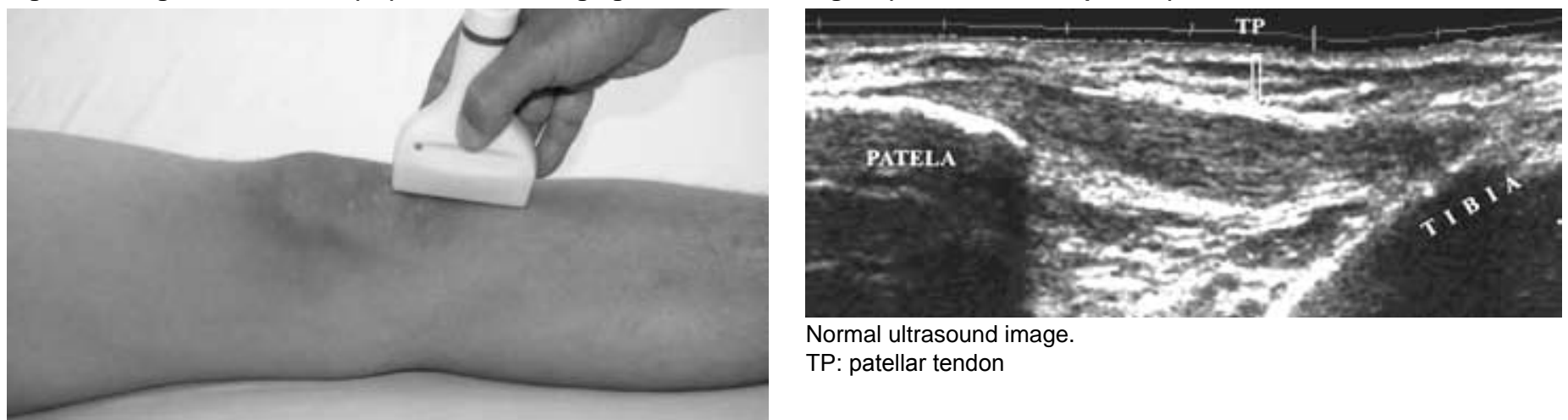

Normal ultrasound image.

TP: patellar tendon 


\section{Original Scientific Articles}

Figure 4: Longitudinal Section (LS) Ultrasound Imaging of the Medial Knee Compartment
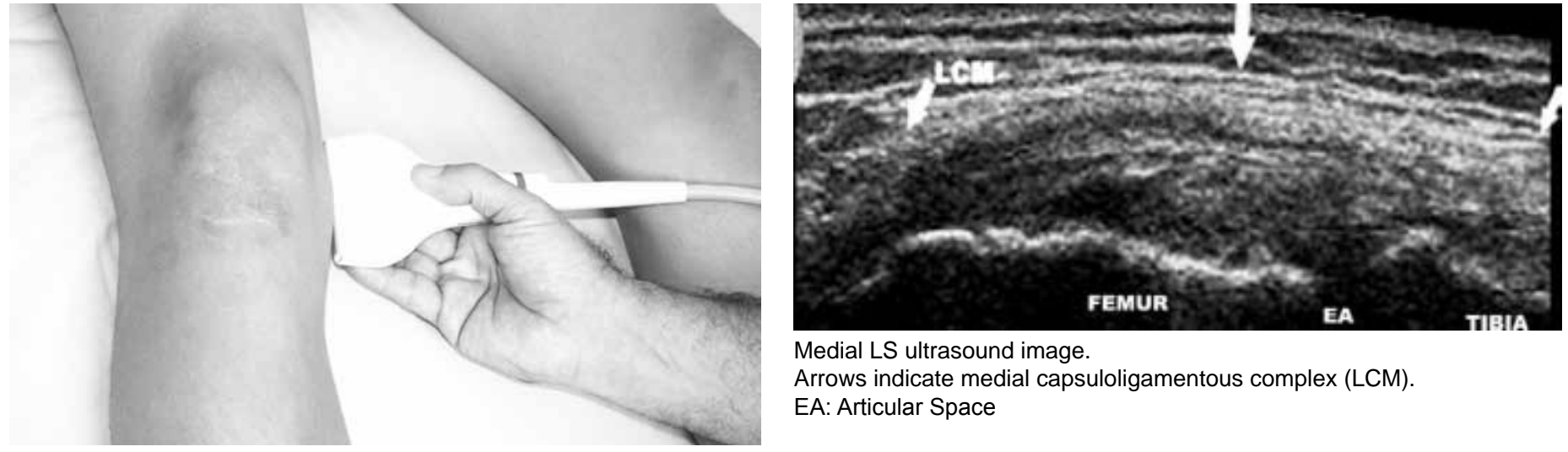

Medial LS ultrasound image.

Arrows indicate medial capsuloligamentous complex (LCM).

EA: Articular Space

Medial LS transducer position.

Figure 5: Longitudinal Section (LS) Ultrasound Imaging of the Lateral Knee Compartment.
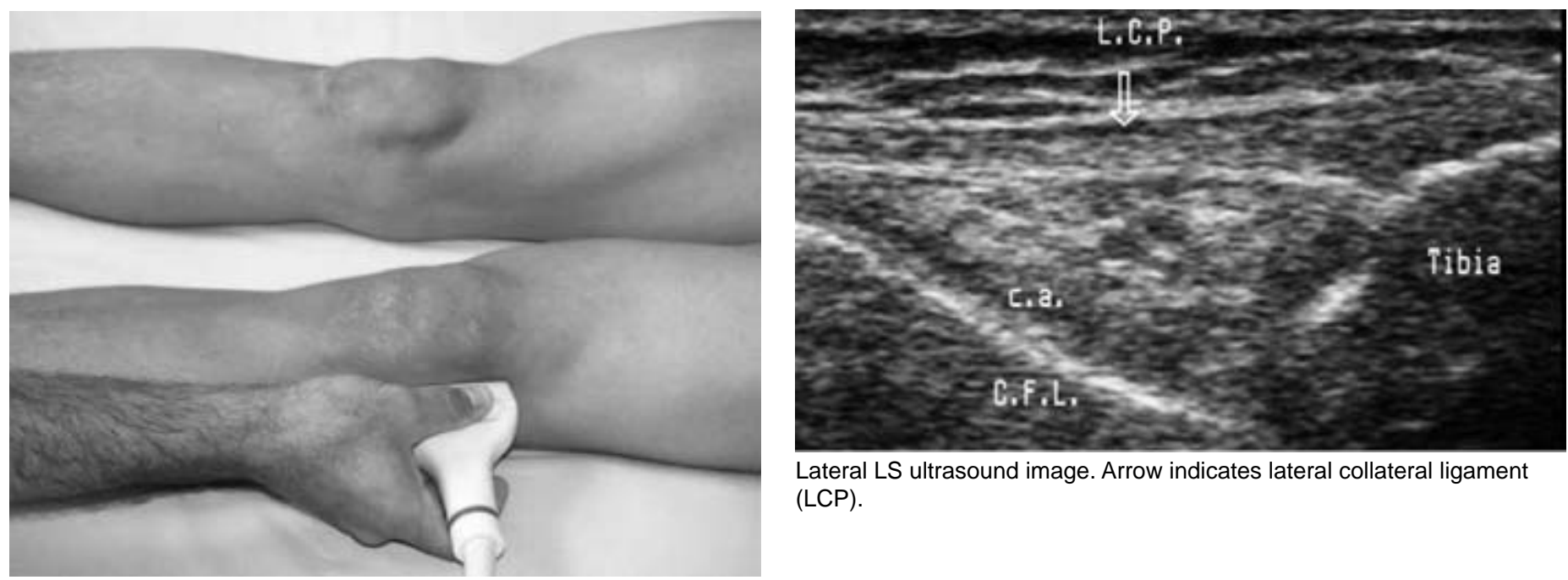

Lateral LS ultrasound image. Arrow indicates lateral collateral ligament (LCP).

Lateral LS transducer position.

Figure 6: Longitudinal Section (LS) Ultrasound Imaging of the Medial Knee Compartment

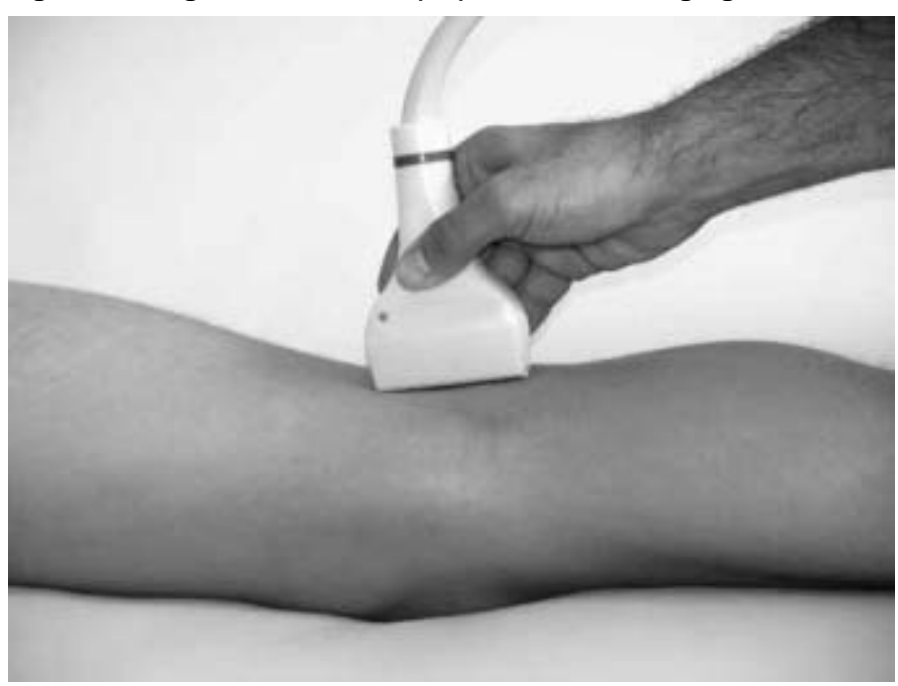

Posterior LS transducer position.

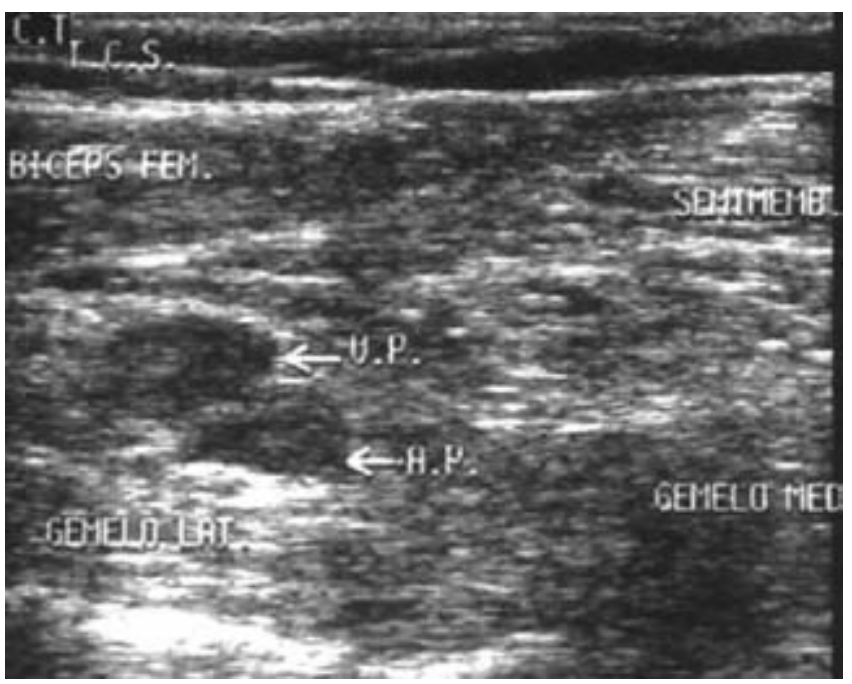

Posterior LS ultrasound image. Arrows indicate popliteal fossa. 
Figure 7: Anillo's Patellofemoral Congruence Ultrasound Method, Determining the RAB angle

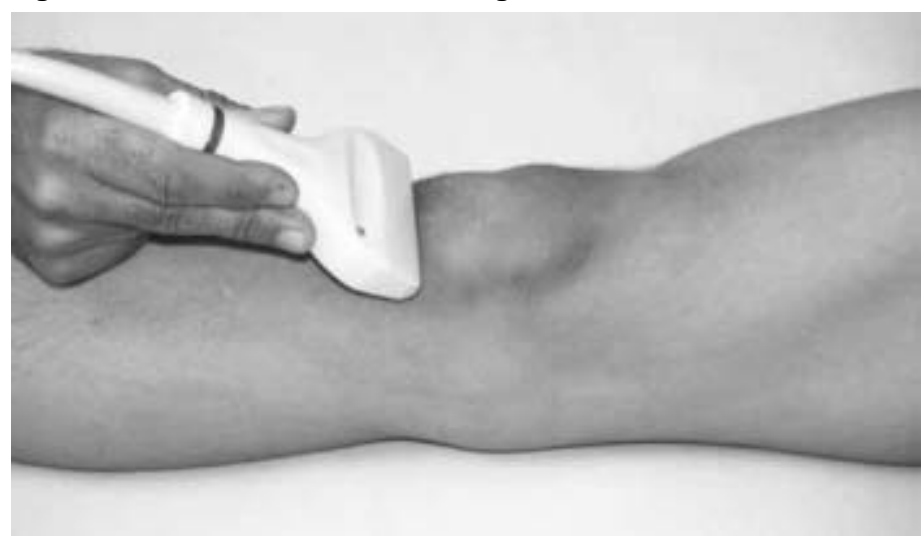

CT transductor position for determining RAB angle.

\section{RESULTS}

Among the 100 athletes in Group B, 57\% showed some alteration of the echostructure in one or both knee joints, compared to ultrasound patterns established as physiologically normal in Group A.

The other 43 athletes showed no ultrasound alterations in their knees, nor any predisposing factor related to overuse sports injuries. Tables 1 and 2 summarize the subclinical conditions detected by ultrasound in Group B, in one or both knees, distributed by sex and sport, respectively. The number of conditions detected in men was higher by a ratio of $3.2 / 1$ (87/27), which is consistent with the predominance of male athletes preselected for the Sydney Olympics, and therefore to the composition of the sample studied: $2.5 / 1(71 / 29)$.

Table 1: Subclinical Alterations in Athletes' Knees Detected with Preventive Ultrasound Diagnostic Imaging Method, by Sex

\begin{tabular}{|l|r|r|r|}
\hline Condition & Men & Women & Total \\
\hline Intra-articular effusion (synovitis) & 22 & 8 & 30 \\
\hline Extensor mechanism alteration & 20 & 6 & 26 \\
\hline $\begin{array}{l}\text { Infrapatellar fat pad heterogeneity } \\
\text { (distortion) }\end{array}$ & 10 & 5 & 15 \\
\hline Meniscal echostructure distortion & 11 & 3 & 14 \\
\hline Extra-articular ligament echostructure distortion & 10 & 1 & 11 \\
\hline $\begin{array}{l}\text { Other intra-articular or periarticular echostruc- } \\
\text { ture alterations }\end{array}$ & 8 & 3 & 11 \\
\hline Articular cartilage echostructure distortion & 6 & 1 & 7 \\
\hline TOTAL & 87 & 27 & 114 \\
\hline
\end{tabular}

Articular effusion (synovitis) was the ultrasound indicator most frequently detected among the athletes studied; it was found in 30 of the 200 knees scanned, predominantly in male athletes who practice combat sports and who jump as part of their forcegenerating movement.

Qualitative evaluation of articular effusion detected took into consideration the characteristics of the synovial fluid and period of evolution. In chronic cases, consistency of the synovial fluid, presence of septa in the bursae, and a certain degree of synovial thickening, with or without a proliferation of villi, were observed. With acute synovitis, the synovial fluid was predominantly clear and anechoic (Figure 8).

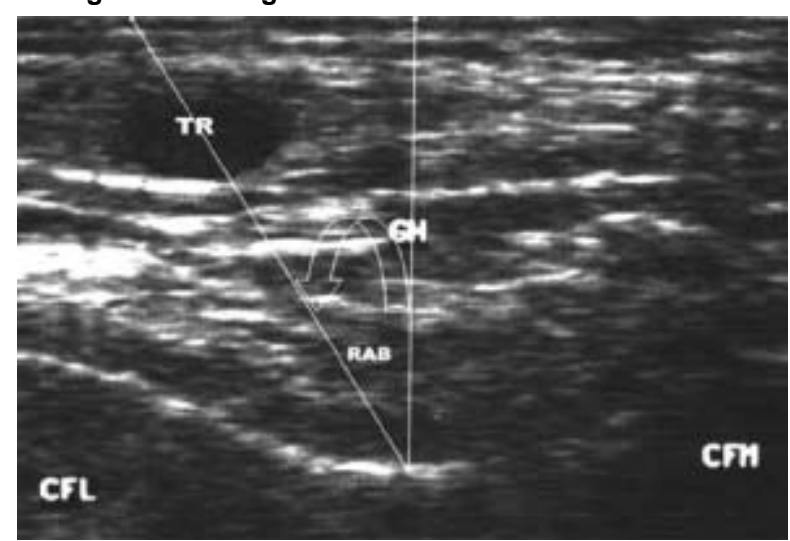

CT ultrasound image of the infrapatellar region showing RAB angle. TR: patellar tendon, GH: infrapatellar (Hoffa's) fat pad, CFL: lateral femoral condyl, CFM: Medial femoral condyl

To establish a normal extensor mechanism pattern, distribution of control group RAB angle values was analyzed. RAB angles from $5^{\circ}$ to $9^{\circ}$ were found in the majority of knees examined in both sexes, and these values were considered within the physiological limits of patellar lateralization (Table 3 ). The average value in men was $6.81^{\circ}$ with a standard deviation (SD) of $3.22^{\circ}$, while the average value in women was $7.82^{\circ}$ with a SD of $3.14^{\circ}$, with $95 \% \mathrm{Cl}$ for both sexes.

Distribution by percentiles of RAB angle values obtained from the 600 knees in Group A is shown in Table 4. Considering the prevalence of extensor mechanism malalignment reported in the specialized literature,[20,21] all Group A knees in the $\geq 95$ percentile range were deemed to have extensor mechanism malalignment. This corresponded to RAB angle values of $\geq 13^{\circ}$ in both sexes.

Based on this standard of normal alignment, 26 extensor mechanism alterations were detected in 16 of the 100 athletes in the study, or $13 \%$ of the 200 knees evaluated, predominantly in sports where jumping is common. Extensor mechanism malalignment with a $\mathrm{RAB}$ angle $\geq 13^{\circ}$ was the most frequently observed (10/26), especially in sports that require athletes with greater average height, such as volleyball. Patellar tendinopathies $(7 / 26)$ and quadriceps tendinopathies $(6 / 26)$ were characterized by an increase in the echogenicity of tendinous insertions, presence of edema between the longitudinal tendinous fascicles, or intratendinous calcifications. Frequency of these alterations was highest among the volleyball players and the weightlifters, in that order.

Echostructure distortion in the medial patellar plica was the most frequent finding (11/15) among alterations detected in the infrapatellar fat pad. This distortion was reported when hypo- or hyperechoic circumscribed nodular images were observed in the TS infrapatellar ultrasound image, surrounded by an anechoic halo with an inflammatory appearance, in contrast with the typical echogenicity of the infrapatellar fat pad, and was also accompanied by thickening of the articular cartilage underlying the medial femoral condyle. This distortion pattern coincides with that described in the literature,[4] and was predominantly observed in athletes that bend their knees deeply, such as baseball catchers, judokas, and fencers. 
Table 2: Subclinical Alterations in Athletes' Knees Detected with Preventive Ultrasound Diagnostic Imaging Method, by Sport

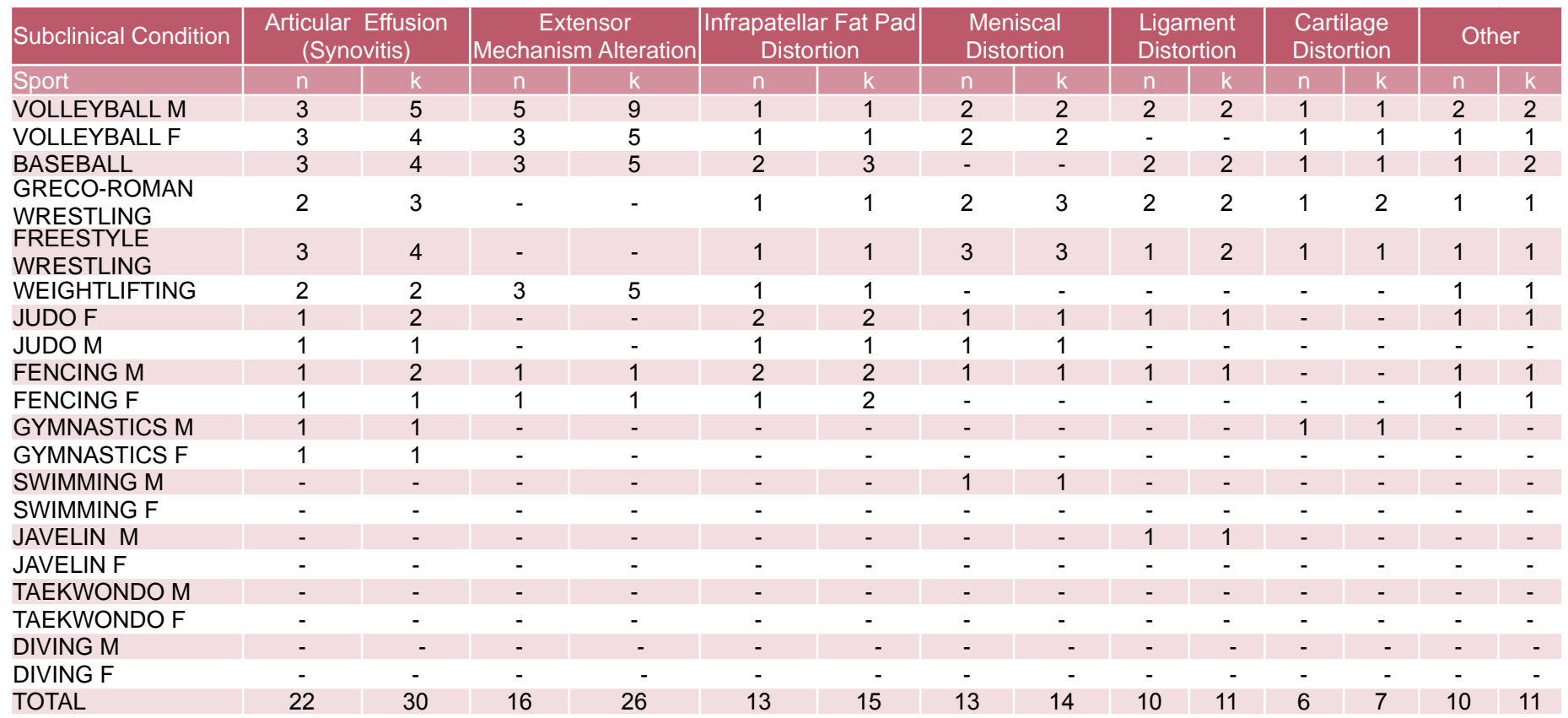

$n$ : number of athletes affected; $k$ : number of knees affected; M: male; F: female

Figure 8: Typical Ultrasound Images of Articular Effusion Detected in Asymptomatic Athletes

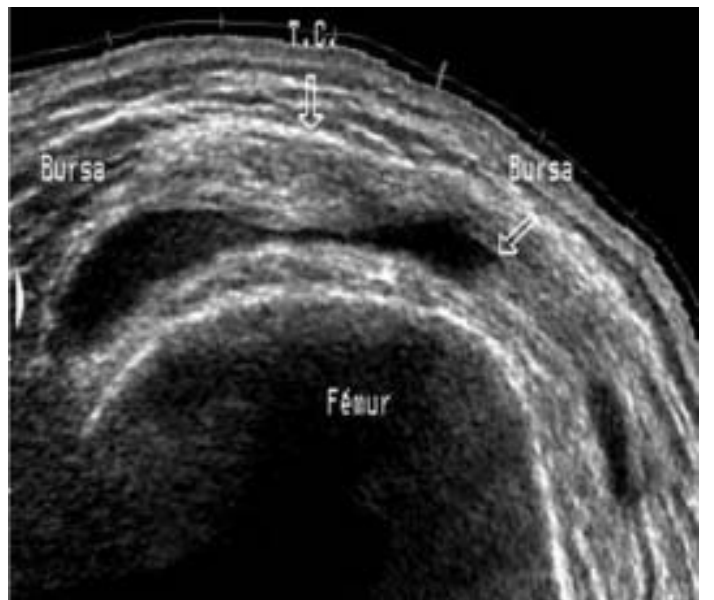

Suprapatellar TS ultrasound image of male volleyball player with slight articular effusion (arrow).

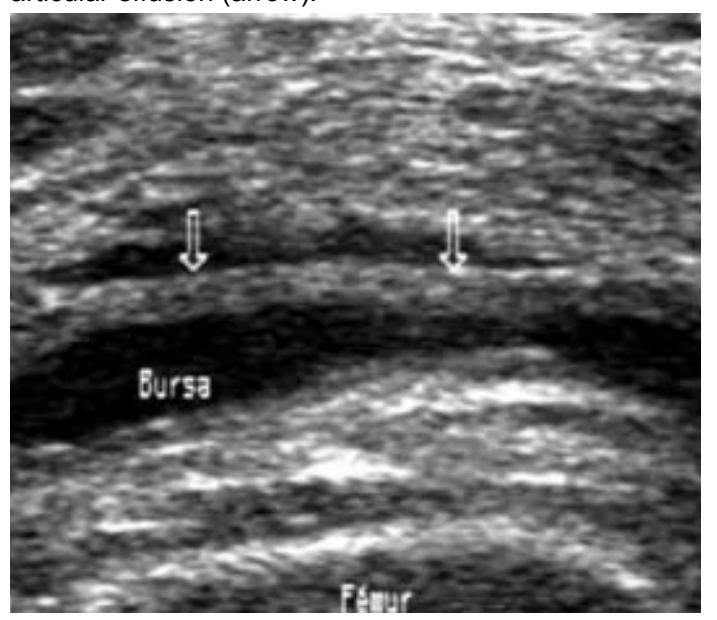

Suprapatellar LS ultrasound image of female volleyball player with chronic articular effusion: synovial proliferation and septum (arrow).

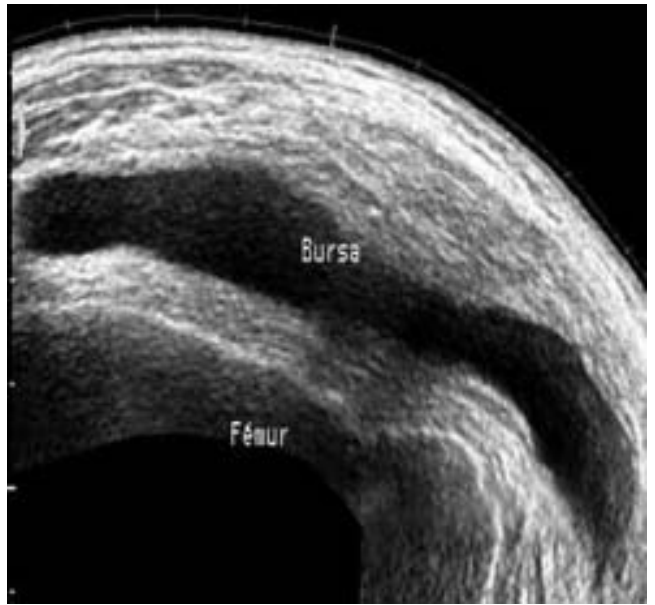

Suprapatellar TS ultrasound image of wrestler with moderate articular effusion involving suprapatellar bursa.

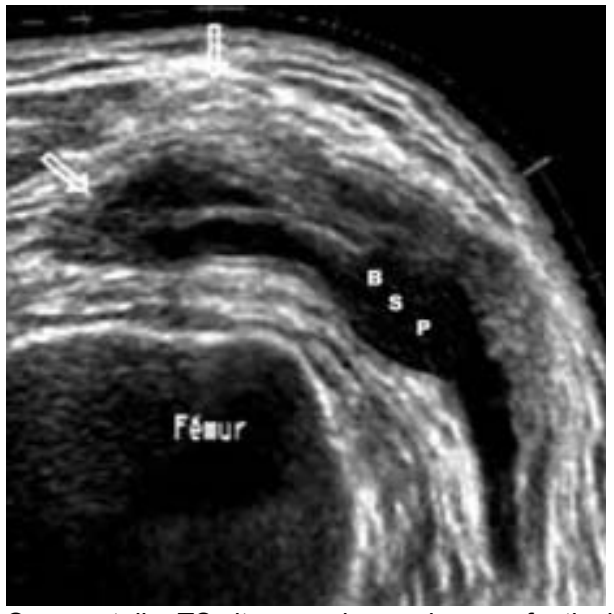

Suprapatellar TS ultrasound zoom image of articular effusion in the same female volleyball player. BSP: suprapatellar bursa (arrow). 
Table 3: Distribution of Control Group RAB Angle Values by Sex

\begin{tabular}{|c|c|c|c|}
\hline \multicolumn{2}{|c|}{ Men } & \multicolumn{2}{|c|}{ Women } \\
\hline $1^{\circ}$ & 06 & $1^{\circ}$ & - \\
\hline $2^{\circ}$ & 10 & $2^{\circ}$ & - \\
\hline $3^{\circ}$ & 13 & $3^{\circ}$ & 03 \\
\hline $4^{\circ}$ & 27 & $4^{\circ}$ & 09 \\
\hline $5^{\circ}$ & 52 & $5^{\circ}$ & 47 \\
\hline $6^{\circ}$ & 30 & $6^{\circ}$ & 54 \\
\hline $7^{\circ}$ & 37 & $7^{\circ}$ & 52 \\
\hline $8^{\circ}$ & 57 & $8^{\circ}$ & 50 \\
\hline $9^{\circ}$ & 32 & $9^{\circ}$ & 33 \\
\hline $10^{\circ}$ & 02 & $11^{\circ}$ & 06 \\
\hline $11^{\circ}$ & 07 & $12^{\circ}$ & 22 \\
\hline $12^{\circ}$ & 09 & $13^{\circ}$ & 08 \\
\hline $13^{\circ}$ & 08 & $14^{\circ}$ & 10 \\
\hline $14^{\circ}$ & 06 & $18^{\circ}$ & 01 \\
\hline $15^{\circ}$ & 01 & $19^{\circ}$ & 01 \\
\hline $16^{\circ}$ & 01 & $20^{\circ}$ & 01 \\
\hline $18^{\circ}$ & 01 & $21^{\circ}$ & 02 \\
\hline $23^{\circ}$ & 01 & $22^{\circ}$ & 01 \\
\hline Total $^{\circ}$ & 300 & Total $^{\circ}$ & 300 \\
\hline
\end{tabular}

Table 4: Distribution of Control Group RAB Angle Values by Percentile

\begin{tabular}{|c|c|}
\hline Percentile & RAB Angle \\
\hline 3 & $2^{\circ}$ \\
5 & $3^{\circ}$ \\
10 & $4^{\circ}$ \\
\hline 25 & $5^{\circ}$ \\
\hline 50 & $7^{\circ}$ \\
75 & $9^{\circ}$ \\
\hline 90 & $12^{\circ}$ \\
95 & $13^{\circ}$ \\
97 & $14^{\circ}$ \\
\hline
\end{tabular}

Mean: $7.31^{\circ}$ Standard deviation: $3.22^{\circ}$

Some form of meniscus pattern distortion was observed in 14 of the 200 knees evaluated in Group B, but was classified as normal based on the pattern established in Group A, as well as reports in specialized literature, which classify a meniscus as distorted when any of its segments shows a loss of form or of characteristic homogeneity.[4,18,19]

Ligament distortion was found in 11 of the 200 knees studied, and articular cartilage distortion was observed in only $7 / 200$, based on evidence of qualitative or quantitative variations in appearance (ligaments) and thickness (cartilage). Eleven other asymptomatic conditions were observed in the 200 athletes' knees evaluated: popliteal cysts (6), anserina bursitis (2), loose bodies (1), popliteal tendinitis (1) and pes anserinus tendinitis (1), none of which predominated in any particular sport.

\section{DISCUSSION}

This study is based on the Preventive Ultrasound Diagnostic Imaging Method developed by the Cuban Sports Medicine Institute for early detection of subclinical musculoskeletal alterations, as a basis for preventive action. This method arose from evaluation of sports injuries: after performing a comparative ultrasound of the contralateral anatomy to better understand alterations in the affected region, it was often found that the supposedly healthy anatomic region displayed similar ultrasound alterations, and patients later developed clinical symptoms.
Regarding detection of subclinical articular effusion (synovitis), it has been established that under normal conditions, the presence of a scant amount of intra-articular fluid can be observed. $[1,3]$ But it has also been shown that any process affecting the synovial membrane provokes edema and stimulates effusion, frequently involving the bursae and the neighboring tendinous sheaths.[4]

Various authors agree that the presence of effusion in the subquadricipital sac (suprapatellar bursa), although a rather vague indicator, is the earliest sign of articular degradation, and that ultrasound is very useful for determining the precise magnitude of articular effusion and other associated characteristics, such as the presence of residual loose bodies from intra-articular injuries, septa, and thickening of the synovial membrane. $[4,18,19]$

Our study confirmed such findings and also verified that the accumulation of fluid in the suprapatellar region occurs predominantly towards the lateral articular recesses, parallel to the edges of the patellofemoral joint. For this reason, ultrasound imaging of the knee must be done comparatively, with longitudinal, transverse, and oblique sections in dorsal decubitus, using dynamic movements, including isometric contractions of the quadriceps, and passive and active flexion and extension of the knee. This technique encourages fluid to flow from the condylar fossae or canals and collect in the suprapatellar region, and allows for better detection of the magnitude of effusion and presence of small bone or cartilage fragments.

This study also demonstrated the advantages of ultrasound compared to clinical and radiographic methods of detecting extensor mechanism alterations. Patellofemoral incongruence due to excessive lateral displacement of the extensor mechanism can be associated with subclinical degradation of the patellar and quadriceps tendons.[3]

When the patella exhibits malaligned movements with respect to the longitudinal axis of the femur, it can suddenly luxate or undergo gradual remodeling (Wolff's Law), which makes the "newly formed" patella incapable of adapting to movements across the femoral condyles, interfering with harmonious execution of highly complex athletic movements.[20-23]

Cailliet, quoting Galeno, who first proposed that "Abnormal alignment of the patella inside the femoral fossa results in clinical pathology and injury," stated that the patella should normally move directly and centrally upwards during contraction of the quadriceps, and that significantly measurable lateral movement indicates excessive lateral pulling. However, even when clinical observation of lateral patellar deviation is clear, it is difficult to measure precisely. This refers to the classic and laborious method of determining the $\mathrm{Q}$-angle, which involves tracing two virtual lines: from the anterior superior iliac spine to the center of the patella, and from the anterior tibial tubercle to the center of the patella.[22]

Different techniques for radiographic evaluation of patellofemoral disorders, such as tangential knee x-rays, arthrography, and CAT, are recognized in the literature, but, given their diversity and complexity, are not practical for determining the degree of malalignment.[3,20,21,23] 
Compared to clinical examination and x-rays, ultrasound has the advantages of immediate results, safety, evident technological advancement, and the potential to make both static and dynamic determinations in real time, thus providing a comprehensive biomechanical evaluation beyond the traditional clinical concept of instability.

Finally, this study established normal reference patterns for ultrasound imaging of the knee, particularly applied to Anillo's Patellofemoral Congruence Ultrasound Method and calculation of the RAB Angle. There are many well-established ultrasound measurement systems for abdominal organs and soft tissue, including the classic Alpha and Beta angles, described by Professor Graf in his study of developmental hip dysplasia in children.[24] Experience with this technique at IMD led to extrapolation of these angles to the anatomical points of the knee essential for determining normal patellar alignment; vectors were then traced, enabling calculation of the angle of patellofemoral incongruence or RAB angle (Figure 7).[3]

In 2000, the Cuban IMD's Imaging Department incorporated RAB angle measurement into its methodology for diagnostic knee examination, and has been improving it since then. As a result, sports medicine specialists at IMD have been able to make early diagnosis of abnormal patellar alignment with respect to the lon- gitudinal axis of the femur, allowing timely preventive action with therapeutic measures aimed at correcting patellofemoral incongruence and preventing complications that could undermine a sports career and even interfere with quality of life once an athlete retires, thus decreasing the risk of permanent physical injuries.

\section{CONCLUSIONS}

Screening for silent sports injuries using IMD's Preventive UItrasound Diagnostic Imaging Method is useful for medical management of athletic conditioning, since it enables early diagnosis of distortions in the articular and periarticular echostructure, as well as visualization of endogenous predisposing factors (such as patellofemoral incongruence) linked to overuse sports injuries in asymptomatic, high-performance athletes, thereby facilitating preventive action.

Systematic application of this method of preventive screening is recommended for medical management of high-performance athletes at all levels, particularly in sports training programs with limited resources.

Further research is also recommended to validate and complement the results of this study, particularly with samples among athletes most affected by overuse knee injuries and who would potentially most benefit from early diagnosis. - - 1 -

\section{REFERENCES}

1. Anillo R. Ecografía profiláctica de la rodilla en voleibolistas del alto rendimiento cubano [master's thesis]. Havana (CU): Higher Institute of Medical Sciences; 2002.

2. Fredberg $U$, Bolvig $L$. Significance of ultrasonographically detected asymptomatic tendinosis in the patellar and achilles tendons of elite soccer players: a longitudinal study. Am J Sports Med. 2002;30:488-91.

3. Anillo R. Ecodiagnóstico preventivo de la rodilla en deportistas cubanos del alto rendimiento [dissertation]. Havana (CU): Higher Institute of Medical Sciences; 2007

4. Valls O, Hernández JL, Anillo R. Ecografía del Aparato Locomotor. Havana: Ciencias Médicas; 2003.

5. Katchburian MV, Bull AMJ, Shih YF, Heatley FW, Amis AA. Measurement of patellar tracking: assessment and analysis of the literature. Clin Orthop Relat Res. 2003;(412):241-59.

6. Kwak SD, Ahmad CS, Gardner TR, Grelsamer $\mathrm{RP}$, Henry $\mathrm{JH}$, Blankevoort L, et al. Hamstrings and iliotibial band forces affect knee kinematics and contact pattern. J Orthop Res. 2000 Jan;18(1):101-8.

7. Mizuno Y, Kumagai M, Mattessich SM, Elias JJ, Ramrattan N, Cosgarea AJ, et al. Q-angle influences tibiofemoral and patellofemoral kinematics. J Orthop Res. 2001 Sep;19(5):834-40

8. Moro-oka T, Matsuda S, Miura H, Nagamine R, Urabe K, Kawano T, et al. Patellar tracking and patellofemoral geometry in deep knee flexion. Clin Orthop Relat Res. 2002 Jan;(394):161-8.

9. Senavongse W, Farahmand $F$, Jones J, Andersen $H$, Bull AM, Amis $A A$, et al. Quantitative measurement of patellofemoral joint stability: force-displacement behavior of the human patella in vitro. J Orthop Res. 2003 Sep;21(5):780-6.

10. Shih YF, Bull AMJ, McGregor AH, Amis AA A technique for the measurement of patel- lar tracking during weightbearing activities using ultrasound. Proc Inst Mech Eng $[\mathrm{H}]$. 2003;217(6):449-57

11. Grelsamer RP. Patellar malalignment. J Bone Joint Surg Am. 2000;82:1639-50.

12. Caldelas E, Zarur N. Rodilla del saltador. Tratamiento quirúrgico artroscópico combinado con rastrillaje y colágeno povidona en deportistas de alto rendimiento. Acta Ortop Mex. 2007 Sept-Oct;21(5):234-8.

13. Lian OB, Engebretsen $L$, Bahr $R$. Prevalence of jumper's knee among elite athletes from different sports: a cross-sectional study. Am J Sports Med. 2005 Apr;33(4):561-7. Epub 2005 Feb 8.

14. Shih $\mathrm{Y}$, Bull AM, McGregor AH, Amis AA. Active patellar tracking measurement: a novel device using ultrasound. Am J Sports Med. 2004 JulAug;32(5):1209-17. Epub 2004 May 18

15. Warden S, Kiss Z, Malara F, Ooi A, Cook J, Crossley $\mathrm{K}$. Comparative accuracy of magnetic resonance imaging and ultrasonography in confirming clinically diagnosed patellar tendinopathy. Am J Sports Med. 2007 Mar;35(3):427-36. Epub 2007 Jan 29.

16. Adler RS, Finzel KC. The complementary roles of MR imaging and Ultrasound of tendons. Radiol Clin North Am. 2005 Jul;43(4):771-807, ix.

17. Ramos JJ, López FJ, Segovia JC, et al. Rehabilitación del paciente con lesión del ligamento cruzado anterior de la rodilla. Rev Int Med Cienc Act Fís Deporte. 2008 Mar;8(29).

18. Lefebvre E, Pourcelot L. Ecografía Musculotendinosa. París: Masson, S.A.;1996.

19. Dondelinger R. Atlas de Ecografía Músculotendinosa. Nueva York: Thieme Med Pub Inc.; 1999.

20. Aglietti P, Cerulli G. Patellar pain and incongruence. I. Measurements of incongruence. Clin Orthop. 1983;176:217-24

21. Insall N, Tria J. Patellar pain and incongruence. Clinical App Clin Orthop.1983;176:225-32.

22. Cailliet R. Síndromes Dolorosos de la Rodilla. México DF: El Manual Moderno S.A.; 1994.
23. Kulund DK. Lesiones del Deportista. Madrid: Salvat Editores SA; 1990.

24. Graf R. Hip sonography- how reliable? Sector scanning up study. J Pediat Orthop (B). 1993;2:115-21.

\section{THE AUTHORS}

Ricardo Anillo Badía (Corresponding Author: anillor@infomed.sld.cu), specialist in sports medicine and medical management of athletic training; full professor, Enrique Cabrera Medical School; head professor of musculoskeletal system ultrasound imaging, and sports medicine and trauma, Sports Medicine Institute, Havana, Cuba.

Emilio Villanueva Cagigas, specialist in sports medicine and medical management of athletic training, Sports Medicine Institute, Havana, Cuba

Dayneri León Valladares, specialist in sports medicine and medical management of athletic training, Sports Medicine Institute, Havana, Cuba.

Armando Víctor Pena Cimadevilla, physiologist and specialist in medical management of athletic training, Sports Medicine Institute, Havana, Cuba.

Submitted: April 29, 2008

Approved for publication: February 27, 2009 